\title{
Solution-Processed All-Perovskite Multi-Junction Solar Cells
}

David P. McMeekin, ${ }^{1}$ Suhas Mahesh, ${ }^{1}$ Nakita K. Noel, ${ }^{1}$ Matthew T. Klug, ${ }^{1}$ JongChul Lim, ${ }^{1}$ Jonathan H.

Warby, ${ }^{1}$ James M. Ball, ${ }^{1}$ Laura M. Herz, ${ }^{1}$ Michael B. Johnston, ${ }^{1}$ and Henry J. Snaith ${ }^{1,2 *}$

${ }^{1}$ Clarendon Laboratory, Department of Physics, University of Oxford, Parks Road, Oxford, OX1 3PU, UK

${ }^{2}$ Lead Contact

*Correspondence: henry.snaith@physics.ox.ac.uk

\section{SUMMARY}

Multi-junction device architectures can increase the power conversion efficiency (PCE) of photovoltaic (PV) cells beyond the single-junction thermodynamic limit. However, these devices are challenging to produce by solution-based methods, where dissolution of underlying layers is problematic. By employing a highly volatile acetonitrile $\left(\mathrm{CH}_{3} \mathrm{CN}\right) /$ methylamine $\left(\mathrm{CH}_{3} \mathrm{NH}_{2}\right)$ (ACN/MA) solvent-based perovskite solution, we demonstrate fully solution-processed absorber, transport and recombination layers for monolithic all-perovskite tandem and triplejunction solar cells. By combining $\mathrm{FA}_{0.83} \mathrm{Cs}_{0.17} \mathrm{~Pb}\left(\mathrm{Br}_{\left.0.7 \mathrm{I}_{0.3}\right)_{3}}(1.94 \mathrm{eV})\right.$ and $\mathrm{MAPb}_{3}$ $(1.57 \mathrm{eV})$ junctions, we reach two-terminal tandem PCEs of over $15 \%$ (steadystate). We show that a $M A \mathrm{~Pb}_{0.75} \mathrm{Sn}_{0.25} I_{3}(1.34 \mathrm{eV})$ narrow band gap perovskite can be processed via the ACN/MA solvent-based system, demonstrating the first, proof-of-concept, monolithic all-perovskite triple-junction solar cell with an open-circuit voltage reaching $2.83 \mathrm{~V}$. Through optical and electronic modeling, we estimate the achievable PCE of a state-of-the-art triple-junction device architecture to be $\mathbf{2 6 . 7 \%}$. Our work opens new possibilities for large-scale, lowcost, printable perovskite multi-junction solar cells.

\section{KEYWORDS}

Perovskite, solar cell, photovoltaic, multi-junction, triple-junction, tandem, monolithic, twoterminal, solution-processed, printable, roll-to-roll

\section{Context \& Scale}

Silicon-based solar cells are dominating today's solar energy market. However, their efficiencies will soon reach their maximum practical limit. Without any gains in efficiency, price reductions will become increasingly difficult to achieve. Tandem and multi-junction architectures can overcome this single-junction efficiency limit. Perovskites materials offer both band gap tunability and solution processability. This unique combination of properties allows for fabrication of multi-junction solar cells using high throughput deposition techniques such as blade coating, roll-to-roll, gravure coating or inkjet printing. However, these solar cells have yet to be fabricated using these deposition techniques, due to difficulties in sequentially depositing these semiconductors. By utilizing an acetonitrile/methylaminebased solvent, we demonstrate the first monolithic all-perovskite multi-junction solar cells fabricated via solution processing of all active layers, apart from the electrodes.

\section{Highlights}

- All-perovskite two-terminal tandem solar cells fabricated via solution processing

- Acetonitrile/methylamine based-solvent can process narrow band gap perovskite

- Revealing the role of excess metal ions for mixed tin/lead perovskite systems

- Proof-of-concept of the first monolithic all-perovskite triple-junction solar cell

\section{eTOC Blurb}

Perovskite solar cells can be processed using solution-based methods. Furthermore, perovskite solar cells can tune their band gap to absorb different portions of the solar spectrum. This property allows for fabrication of multi-junction solar cell, which can offer higher power 
conversion efficiencies than single-junction architecture. Here, we combine both features to fabricate the first solution-processed, monolithic, all-perovskite tandem and triple-junction solar cells.

\section{INTRODUCTION}

Metal halide perovskite semiconductors exhibit high performance when integrated in optoelectronic devices such as light-emitting-diodes (LEDs),[1] photo-detectors,[2,3] lasers[4,5] and solar cells. [6-13] Perovskites have a general chemical formula $\mathrm{ABX}_{3}$, and allow their band gap to be tuned by substituting their chemical constituents, for example the A-site cation can be methylammonium, formamidinium or cesium, the B-site metal cation can be lead or tin, and X-site anion can be iodide, bromide or chloride, or more complex mixtures. This ease of ion substitution enables halide perovskite semiconductors to be tuned to absorb specific regions of the solar spectrum. $[14,15]$

Solar light is composed of a broad energy spectrum with significant intensity ranging from ultraviolet, with photon energies greater than $3 \mathrm{eV}$, to the infrared region with photon energies less than $1.7 \mathrm{eV}$ to around $0.5 \mathrm{eV}$. When light is incident upon a semiconductor, light with energy greater than the band gap is absorbed, and the excess energy of the photons (above the band gap energy) is lost as heat through thermalisation of the electrons. Due to the thermalisation process, the maximum voltage a PV cell can generate is always slightly less than the band gap energy, and the maximum solar to electrical power conversion efficiency of a PV cell is obtained for a semiconductor with a band gap which results in maximizing the product of voltage times current density. This has been calculated by Shockley and Queisser[16] and Tiedje-Yablonovitch,[17] who estimate the ideal band gap of a PV cell. Furthermore, this compromise between current and voltage places an absolute limit upon efficiency for PV cells composed of a single absorber layer to around 32.5\%.[18] By reducing the difference between the photon energy and the electronic band gap energy, we can effectively minimize chargecarrier thermalisation losses. However, in order to capture a significant fraction of the sun light, multiple cells with different band gaps need to be stacked on top of each other, known as multijunction cells. Through this approach it is possible to raise the theoretical efficiency limit under 1 sun AM1.5 irradiance to 44.3 and $50.1 \%$ for double and triple junction cells, respectively.[19]

Recently, efficient solar cells employing wide-band gap perovskites have been fabricated by partial substitution of the organic A-site cation with cesium (Cs) to improve their structural, thermal, and light stability.[20-30] Furthermore, narrow band gap materials have also been explored through modifications to the B-site cation, where the partial substitution of lead $(\mathrm{Pb})$ with tin ( $\mathrm{Sn})$ results in an anomalous band gap bowing behavior, leading to band gaps approaching $1.2 \mathrm{eV} \cdot[31-39]$

To date, perovskite solar cells exhibiting record efficiencies have been processed via solutionbased fabrication methods, reaching $23.3 \%$ in a single junction device.[40] The ability to fabricate high quality absorber materials from solution-based processes has led to the rapid rise of perovskites solar cells. [6-13,41] In recent years, significant breakthroughs have been made in four-terminal (4T)[34,39,42 - 47] and two-terminal (2T)[24,39,48 - 53] perovskite-onsilicon,[42,43,46,49,51,54,55] perovskite-on-Cu(In,Ga)Se ${ }_{2} \quad$ (CIGS), $[42,44,47,48,52]$ perovskite-on- $\mathrm{Cu}_{2} \mathrm{ZnSn}(\mathrm{S}, \mathrm{Se})_{4} \quad$ (CZTSSe)[48] and also perovskite-onperovskite[24,34,39,45,50,56-58] tandem cells. Moreover, Werner and al. recently fabricated the first perovskite/perovskite/silicon triple-junction solar cell, in a step towards highly efficient photovoltaics.[59] Tandem solar cells require a semi-transparent electrode and/or recombination layers between each sub-cell. These highly conductive transparent layers have been fabricated using silver nanowires (Ag-NWs),[42] doped organic semiconductors such as N4,N4,N4",N4"'-tetra([1,1'-biphenyl]-4-yl)-[1,1':4',1"'-terphenyl]-4,4"'-diamine doped with 2,2'-(perfluoronaphthalene-2,6-diylidene) dimalononitrile (TaTm:F6-TCNNQ),[50] poly(3,4ethylenedioxythiophene) polystyrene sulfonate (PEDOT:PSS),[56,60] aluminum doped zinc oxide (AZO)[44], and most notably indium tin oxide (ITO)[24,34,45,48,49,53-55,61]. These materials can also be processed using different deposition techniques such as: spraycoating,[42] film transfer lamination,[60] vacuum deposition[50], and sputter coating $[24,34,44,48,49,54,55,61]$. Sputtered ITO has gained considerable attention due to its high optical transparency throughout the visible and near-infrared (NIR) region, combined with a low resistivity. [62] Due to its dense and compact nature, this sputtered transparent conductive oxide (TCO) can also serve as a physical barrier to the solvents that are used to process the subsequent material layers; specifically, dimethyl formamide (DMF) and dimethyl sulfoxide (DMSO), both strongly coordinating solvents used in the dissolution of perovskite 
salts. These solvents rapidly re-dissolve any underlying perovskite layers unless they are protected by a dense pin-hole free layer, such as indium oxide tin oxide (ITO). Eperon and Leijtens et al. showed that monolithic all-perovskite tandem cells can be fabricated using this dense, sputtered ITO layer.[39] Using this ITO interlayer, D. Zhao et al. recently fabricated an all-perovskite tandem reaching a power conversion efficiencies (PCEs) of 20.7\%.[63] However, the re-dissolution problem has thus far prevented any experimental realization of a multi-junction perovskite solar cell being fabricated with all the active layers between the electrodes being solution processed.[39] These sputter coated TCOs usually require high vacuum deposition systems and additional buffer layers comprised of metal oxides deposited via atomic layer deposition (ALD), with the latter to prevent sputter damage of the organic and perovskite layers. Furthermore, the lower refractive index of ITO, in comparison to the perovskite absorber layers, introduces significant internal reflective losses, thus limiting the maximum feasible power conversion efficiency.[64]

Herein, we employ an acetonitrile/methylamine (ACN/MA) composite solvent, which was previously introduced by Noel et al.,[65] to enable the sequential processing of perovskite absorber layers upon underlying perovskite devices. This fully solution-processed active, transport and recombination layers for perovskite multi-junction architectures have the potential of being applied to the manufacturing of large area films on both rigid and flexible substrates, using deposition techniques such as roll-to-roll (R2R) processing, blade coating or inkjet printing. However, we note that additional work is required to solution-process both transparent and metal electrodes. Here, our solution processed tandem architecture, reaches over $15 \%$ steady-state power conversion efficiency (PCE), and delivers $2.18 \mathrm{~V}$ open circuit voltage $\left(\mathrm{V}_{\text {oc }}\right)$. Furthermore, we show that the mixed-metal $\mathrm{Sn} / \mathrm{Pb}$ perovskite $\mathrm{MAPb}_{0.75} \mathrm{Sn}_{0.25} \mathrm{I}_{3}$, can also be processed via the ACN/MA solvent system, where the reducing nature of MA obviates the need to use $\mathrm{SnF}_{2}$ to achieve respectable efficiencies, allowing us to obtain a scanned PCE of over $11 \%$ (steady-state 10.5\%), employing an n-i-p architecture. Using a mixed-metal $\mathrm{MAPb}_{0.75} \mathrm{Sn}_{0.25} \mathrm{I}_{3}$ perovskite material to extend the light absorption of the multijunction cell to $925 \mathrm{~nm}$, we present the first all-perovskite, monolithic, triple-junction solar cell with a $\mathrm{V}_{\mathrm{oc}}$ of $2.83 \mathrm{~V}$. We utilize an optical and electronic model to validate our experimental results, and reveal the optical losses existing within our specific experimental architecture. We then proceed to model a triple junction perovskite solar cell, using electronic characteristics of currently feasible 1.94/1.57/1.24 eV perovskite materials, showing the possibility of achieving a triple junction device with a $26.7 \%$ PCE and corresponding $\mathrm{V}_{\mathrm{OC}}$ of $3.16 \mathrm{~V}$.

\section{RESULTS and DISCUSSION}

Due to charge conservation, the current density flowing out of each sub-cell in a multi-junction cell must match, and hence the current will be limited by the lowest current density generated from any sub-cell. Thus, in order to maximize the photocurrent density in a $2 \mathrm{~T}$ monolithic tandem, both sub-cells should generate equal current density, which can be achieved through carefully tuning the band gap and thickness of each junction. In the first instance we develop a wide band gap, lead-based perovskite tandem cell by processing a $\sim 1.94 \mathrm{eV}$ (as determined by a Tauc plot which we show in Figure S1) front-cell, to complement a $1.57 \mathrm{eV}$ rear cell. We process the wide band-gap junction first, and hence do not have to overtly consider solvent orthogonality issues. We therefore follow a conventional solution processing route and fabricate $\mathrm{FA}_{0.83} \mathrm{Cs}_{0.17} \mathrm{~Pb}\left(\mathrm{Br}_{0.7} \mathrm{I}_{0.3}\right)_{3}$ with $2 \%$ (molarity with respect to the $\mathrm{Pb}$ ) potassium $\left(\mathrm{K}^{+}\right)$ additive.[66-70] As we have previously described, we employed a deposition technique utilizing hydrohalic acidic, as additives, to fabricate highly ordered perovskite materials with grains reaching micron sizes in diameter (Figure S2).[71] Highly crystalline perovskite materials with low energetic disorder have been shown to suppress halide segregation. [72] Furthermore, as recent reports suggest,[66-69,73] we utilize potassium as an additive to suppress ionic migration and reduce the anomalous hysteretic behavior intrinsically present in perovskite solar cells.[74] For this absorber material, in single junction perovskite solar cells, we obtain open-circuit voltages of up to $1.27 \mathrm{~V}$ and a steady-state power conversion efficiency of $10.9 \%$, which we show in Figure S3. However, although our open-circuit voltages are higher, compared to other $\sim 1.75 \mathrm{eV}$ materials, [75] we note that the voltage losses, with respect to the band gap energy, are greater for this bromide-rich wide-band gap material. Hence, additional efforts are required to further increase $\mathrm{V}_{\mathrm{oc}}$ and minimize non-radiative losses.

All-perovskite monolithic $2 \mathrm{~T}$ tandems and multi-junction solar cells require a tunnel junction (TJ) or recombination layer to provide a means to create an electronic series connection between the different sub-cells. Recombination layers between the sub cells must fulfill stringent requirements. Firstly, they must enable ohmic contact to the charge extraction layers, 
and facilitate recombination of collected electrons and holes without introducing resistive losses. Secondly, they must be as optically transparent as possible to avoid parasitic absorption of light. Thirdly, deposition of the recombination layer should not damage any of the layers beneath, which is typically achieved via introducing "buffer layers" when sputtering, or by using orthogonal solvents for solution processing. Lastly, this interlayer must be a sufficient barrier to solvent penetration to prevent any re-dissolution of underlying perovskite or other electronic layers when subsequently processing another perovskite or charge extraction layer on top. Here, we introduce a recombination layer and an n-i-p perovskite solar cell architecture that meets these constraints. For the recombination layer, we find that a combination of a PEDOT:PSS followed by a ITO nanoparticles works well.
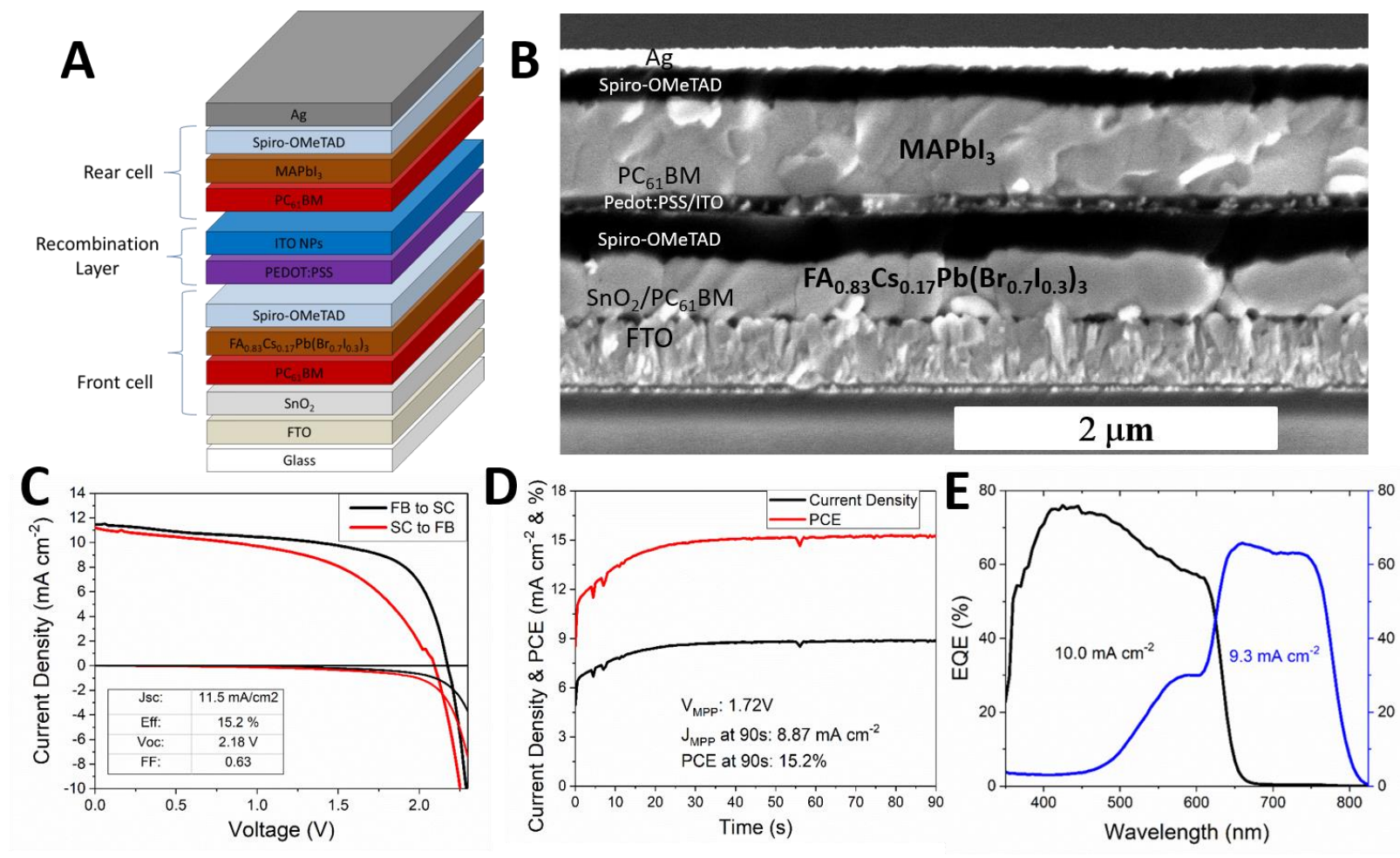

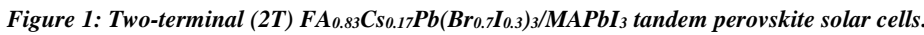

A) Schematics showing an all-solution processed perovskite/perovskite two-terminal (2T) tandem perovskite solar cell. Incoming light will be from below the device.

B) SEM cross-section of the $2 T$ perovskite/perovskite tandem.

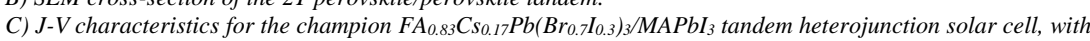
an equivalent irradiance of $104.25 \mathrm{~mW} \mathrm{~cm}^{-2}$, measured at a $0.25 \mathrm{~V} / \mathrm{s}$ scan rate. The active area of the solar cell is $0.0919 \mathrm{~cm}^{-2}$

D) Photocurrent density and power conversion efficiency of champion $\mathrm{FA}_{0.83} \mathrm{Cs} \mathrm{s}_{0.17} \mathrm{~Pb}\left(\mathrm{Br}_{0.7} \mathrm{I}_{0.3}\right)_{3} / \mathrm{MAPbI}_{3}$ tandem heterojunction solar cell measured at the maximum power point for a $60 \mathrm{~s}$ time span

E) EQE spectrum for each sub-cell, and the integrated current density for the tandem perovskite solar cell.

For the rear cell, which is processed on top of the wide-gap cell, we must consider the issue of dissolution of the underlying perovskite film. If we simply employ one of the standard DMF/DMSO solvent based routes, we completely solvate and discolor the underlying perovskite film, even with our recombination layer present, making it evident that our recombination layer is not impermeable to DMF or DMSO (which we show in supplementary video). We have previously developed an ACN/MA based composite solvent system for processing perovskite films, which has several distinct advantages.[71] Firstly, it is much more volatile than DMF, enabling very rapid drying. Secondly, the solvation strength can be tuned by varying the amount of methylamine incorporated. We chose the right amount of MA to enable complete dissolution of the salts, but with minimal excess. We found that having an excess amount of MA in solution has a detrimental impact to the device. Unwanted pinholes in the interlayers may result in methylamine percolating and re-dissolving the perovskite underlayer. We find this solubility point by slowly adding an MA saturated ACN/MA 
perovskite solution to a neat ACN perovskite dispersion, until the mixture becomes a clear perovskite solution.

To achieve optimal results, we found that careful tuning of the B-site metal ion content was needed for both $\mathrm{MAPbI}_{3}$ and $\mathrm{MAPb}_{0.75} \mathrm{Sn}_{0.25} \mathrm{I}_{3}$ perovskite material processed via the ACN/MA solvent route. Effects of non-stoichiometric perovskite precursor solutions have been regularly discussed,[76-80] however the research community has yet to unanimously agree on which precise "non-stoichiometry" is ideal. Some studies have shown that excess organic ammonium, lead to performance gains, while other studies showed the benefits of having excess $\mathrm{PbI}_{2}$ in the precursor solution. However, it is clear that these small stoichiometric changes do impact the perovskite in various ways, ranging from effects on morphology,[77] luminescence [78], trap passivation[79] and stability.[80]

In Figure S4, we show a series of scanning electron microscope (SEM) top view images of an $\mathrm{MAPbI}_{3}$ perovskite film processed with the ACN/MA solvent system, with various nonstoichiometric compositions, ranging from 6\% excess MAI to 6\% excess $\mathrm{PbI}_{2}$. We fabricated these films on top of the $\mathrm{FA}_{0.83} \mathrm{Cs} 0.17 \mathrm{~Pb}\left(\mathrm{Br}_{0.7} \mathrm{I}_{0.3}\right)_{3}$ front-cell, including the PEDOT:PSS/ITO layer and a phenyl- $\mathrm{C}_{61}$-butyric acid methyl ester $\left(\mathrm{PC}_{61} \mathrm{BM}\right)$ electron extraction layer. We observed an impact on the morphology and surface coverage for precursor solutions with different compositions. In a solution processed tandem architecture, it is imperative to eliminate the presence of pinholes, to prevent dissolution of underlying layers. In Figure S5, we show the tandem solar cell performance for devices processed with the differing range of compositions. We find that the ideal composition for maximizing the cell efficiency includes $3 \%$ excess MAI, and proceed to optimize complete tandem solar cells with this composition. In Figure 1B and Figure 1C, we show a schematic of a $2 \mathrm{~T}$ tandem along with a corresponding scanning electron microscopy SEM cross-section image. We fabricate the solar cells in the conventional $n-i-p$ architecture, and find that a recombination layer composed of PEDOT:PSS followed by indium tin oxide (ITO) nanoparticles works remarkably well, sandwiched between a 2,2',7,7'-tetrakis(N, $\mathrm{N}^{\prime}$-di-p-methoxyphenylamine)-9, $9^{\prime}$-spirobifluorene (spiro-OMeTAD) $\mathrm{p}$ type charge extraction layer and $\mathrm{n}$-doped $\mathrm{PC}_{61} \mathrm{BM}$ electron transporter.

In Figure $1 \mathrm{C}$, we show the forward and backwards current-density voltage $(\mathrm{J}-\mathrm{V})$ characteristics of one of our highest-performing two-terminal tandem solar cells measured under a simulated air mass (AM) 1.5 solar irradiation with an equivalent mismatch corrected irradiance of 104.25 $\mathrm{mW} \mathrm{cm}{ }^{-2}$ upon the test cell. Our best tandem device generated a short-circuit current-density $\left(\mathrm{J}_{\mathrm{SC}}\right.$ ) of $11.5 \mathrm{~mA} \mathrm{~cm}{ }^{-2}$ (corrected to $11.0 \mathrm{~mA} \mathrm{~cm}{ }^{-2}$ under $100 \mathrm{mWcm}^{-2} \mathrm{AM} 1.5$ ), a fill-factor (FF) of 0.63 , an open-circuit voltage $\left(\mathrm{V}_{\mathrm{oc}}\right)$ of $2.18 \mathrm{~V}$, giving a $15.22 \% \mathrm{JV}$ determined power conversion efficiency, and a power conversion efficiency of $15.20 \%$ under steady-state power output (SPO) conditions. In Figure 1D we show the SPO, along with a histogram of performance parameters for a large batch of devices in Figure S6. We show in Figure 1E an external quantum efficiency (EQE) of both junctions, with an integrated current density of $10.0 \mathrm{~mA} \mathrm{~cm}^{-2}$ for the front-cell and $9.3 \mathrm{~mA} \mathrm{~cm}^{-2}$ for the rear cell. During the EQE measurement, we applied a voltage bias to the solar cell equal to the $\mathrm{V}_{\mathrm{oc}}$ of the optically biased sub-cell. This allowed for the EQE to be measured near $\mathbf{J}_{\mathrm{sc}}$. We note a moderate current-density mismatch between the two sub-cells. In Table S1 we show the calculated mismatch factor for each material used in the multi-junction solar cell. We note that the xenon arc lamp spectrum can be significantly different to the AM1.5G spectrum due to the large intensity spikes in the infrared portion of the spectrum (shown in Figure S7). As a result, specific sub-cells of the multijunction solar cell may be over or underestimated. In this specific case here, our tandem cell would be rear cell limited under AM1.5G spectrum, but front cell limited under the solar simulator lamp. To account for these discrepancies, we applied a mismatch factor correction with a KG5 filtered silicon reference cell, which reduced our estimated efficiency by a small factor of 1.004. The numbers we quote above are mismatch corrected. In the case of the triplejunction, which we will discuss later on, a significant mismatch factor arises due to the xenon intensity spikes, which requires a reduction in efficiency by a factor of 1.486 to account for this mismatch factor when calibrating with a KG2 filtered silicon reference cell. As we show in Table S2, we have applied both correction factors to our reported efficiencies. Hence, in combination with our KG5 and KG2 Si reference cell measured at $103.83 \mathrm{~mW} \mathrm{~cm}^{-2}$ and 98.83 $\mathrm{mW} \mathrm{cm}$, for the tandem and triple-junction solar cell, respectively, our equivalent AM1.5 irradiances are $104.25 \mathrm{~mW} \mathrm{~cm}^{-2}$ and $146.86 \mathrm{~mW} \mathrm{~cm}^{-2}$ for each solar cell architecture. We do note however, that although we can accurately account for the spectral differences between the solar simulator and AM1.5 spectrum, we cannot accurately account for any change in fill factor, which may occur due to a difference between the sub cell current mismatch under the different spectra. When the current between sub cells in a tandem cell is mismatched, then the FF is increased in comparison with the perfectly matched scenario. This positively compensates for 
current mismatch under real world changing spectra, but adds complications with efficiency estimations with single zone solar simulators. For our tandem cell here, our sub cells are more mismatched under true AM1.5 irradiance, than under our simulator (due to the poor red response of our tandem cell, and higher IR irradiance of our solar simulator). Therefore, if there is a significant impact from this effect, it would lead to a lower FF under our simulated light, than under AM1.5 irradiance.

Estimation of voltage losses is a criticalmetric to access the quality of the recombination interlayers. As we show in Figure S8, using a PEDOT:PSS/ITO NPs interlayers as the recombination layer, we measured a $2 \mathrm{~T}$ tandem $\mathrm{V}_{\mathrm{oc}}$ as high as $2.22 \mathrm{~V}$, resulting in a interlayer voltage loss of approximately $160 \mathrm{mV}$, if we assume both sub-cells generated the highest measured single junction $\mathrm{V}_{\text {oc }}$ of $1.27 \mathrm{~V}$ for the front cell and $1.11 \mathrm{~V}$ for the rear cell, under 1 sun illumination. However, we note that the rear cell will only be illuminated with half a sun in a tandem architecture, resulting in an $\sim 18 \mathrm{mV}$ loss in $\mathrm{V}_{\mathrm{oc}}$ (assuming an ideality factor of 1), which reduces the losses attributed the interlayer to approximately $140 \mathrm{mV}$.

The long-term stability of our tandem architecture is a critical aspect which requires consideration. We note that the ACN/MA based composite solvent system has been shown to readily dissolve methylammonium-based perovskites, however, due to poor salt solubility, more stable perovskites composed of FA and Cs mixed-cation have yet to be fabricated using this solvent system. This inability to incorporate these ions, may ultimately limit the attainable stability of our multi-junction solar cell. To address this issue, we have developed a posttreatment, which incorporates $\mathrm{FA}^{+}, \mathrm{Cs}^{+}$and $\mathrm{Br}^{-}$ions into the $\mathrm{MAPbI}_{3}$ crystal lattice while preserving a similar band gap and efficiency, which we show in Figure S9. This allows for partial substitution of the $\mathrm{MA}^{+}$and $\mathrm{I}^{-}$ions with $\mathrm{FA}^{+}, \mathrm{Cs}^{+}$and $\mathrm{Br}^{-}$ions, forming an (FA,MA, $\mathrm{Cs}) \mathrm{Pb}(\mathrm{Br}, \mathrm{I})_{3}$ material, thus enabling a pathway to stability using the ACN/MA solvent system. We show in Figure S10 that films of our mixed-cation lead mixed halide (FA, MA, $\mathrm{Cs}) \mathrm{Pb}(\mathrm{Br}, \mathrm{I})_{3}$ material, processed from the $\mathrm{MA} / \mathrm{ACN}$ solvent and post-treatment, show much greater thermal stability than films of $\mathrm{MAPbI}_{3}$ processed from the same solvent, when stressed at $130^{\circ} \mathrm{C}$ in a nitrogen atmosphere.

Our recombination layer comprises PEDOT:PSS and indium tin oxide (ITO) nanoparticle (NP) sublayers. We dilute a high conductivity PEDOT:PSS (Heraus H1000) solution with isopropanol (IPA) and directly spin-coat upon the spiro-OMeTAD layer, which acts as both a recombination layer and a partial solvent barrier. We then spin-coat an ITO layer on top, from a solvent dispersion of ITO nanoparticles $(>100 \mathrm{~nm})$. The fabricated ITO nanoparticle layer may be porous and non-continuous. However, these nanoparticles, improve the recombination process, presumably due to their high carrier density, which allow holes from PEDOT:PSS and electrons from $\mathrm{PC}_{61} \mathrm{BM}$ to recombine. PEDOT:PSS is usually considered to be a material which may introduce instability into perovskite solar cells, due to its hygroscopic nature.[81] In order test how stable our recombination layer is, we fabricated single junction cells with the $(\mathrm{FA}, \mathrm{Cs}) \mathrm{Pb}(\mathrm{Br}, \mathrm{I})_{3}$ perovskite processed from a $\mathrm{DMF}$ solvent, with the addition of the complete recombination layer, including the PCBM electron transport layer, between the spiroOMeTAD hole-transport layer and the gold electrode. We stressed the un-encapsulated devices at $85^{\circ} \mathrm{C}$ in an oven in an air atmosphere (ambient humidity $\sim 50 \%$ ), for over 1000 hours, and show the results in Figure S11. Unexpectedly, we observed an improvement in the thermal stability of the cells with the addition of our recombination layer, with the cells retaining over $70 \%$ of their initial performance after 1000 hours aging. This indicates that the added layers are not only relatively stable, but act as a partial encapsulant for the perovskite devices. However, we note that spiro-OMeTAD, along with its dopants, should ultimately be replaced with a more thermally stable hole accepting layer to improve the overall stability of the device stack.

Although neat lead-based devices have led to relatively stable perovskite materials, the drive to narrow the bandgap using less stable tin-based perovskites is still highly desirable for tandem applications.[82] As we show in Figure 2, we also studied the impact of non-stoichiometric precursor solutions on the material properties of the $\mathrm{MAPb}_{0.75} \mathrm{Sn}_{0.25} \mathrm{I}_{3}$ perovskite (with a band gap of $1.34 \mathrm{eV}$ determined from Tauc plots, Figure S12) by tuning the A-site to B-site ratio. In order to keep the intended $\mathrm{MAPb}_{0.75} \mathrm{Sn}_{0.25} \mathrm{I}_{3}$ perovskite composition, we added excess $\mathrm{PbI}_{2}$ and $\mathrm{SnI}_{2}$ at a ratio of 75 to 25. In Figure 2A we show Kelvin probe force microscopy (KPFM) images, and observe a stark increase in work function as we incorporate excess metal ions in the $\mathrm{MAPb}_{0.75} \mathrm{Sn}_{0.25} \mathrm{I}_{3}$ perovskite precursor solution. We also notice slower time-resolved photoluminescence (PL) decays, which we show in Figure 2B. In Figure $2 \mathrm{C}$ we present the transient photo-conductivity for the corresponding samples for a range of excitation densities, measuring maximum perturbation of conductivity decay after photoexcitation by a $3.7 \mathrm{~ns}$ full 
width half maximum laser pulse.[83] Similarly, we observe an increase in early time photoconductivity for films with excess metals ions, implying higher charge carrier mobility, or a small fraction of very rapid trapping on a shorter time-scale than the laser pulse (sub few ns). We find that these longer-lived carrier lifetimes and higher photo-conductivities correlate to a substantial increase in device performance (Figure S13), which results in an optimized $\mathrm{MAPb}_{0.75} \mathrm{Sn}_{0.25} \mathrm{I}_{3} \mathrm{PCE}$ of over $11 \%$, as we show in Figure 2D.
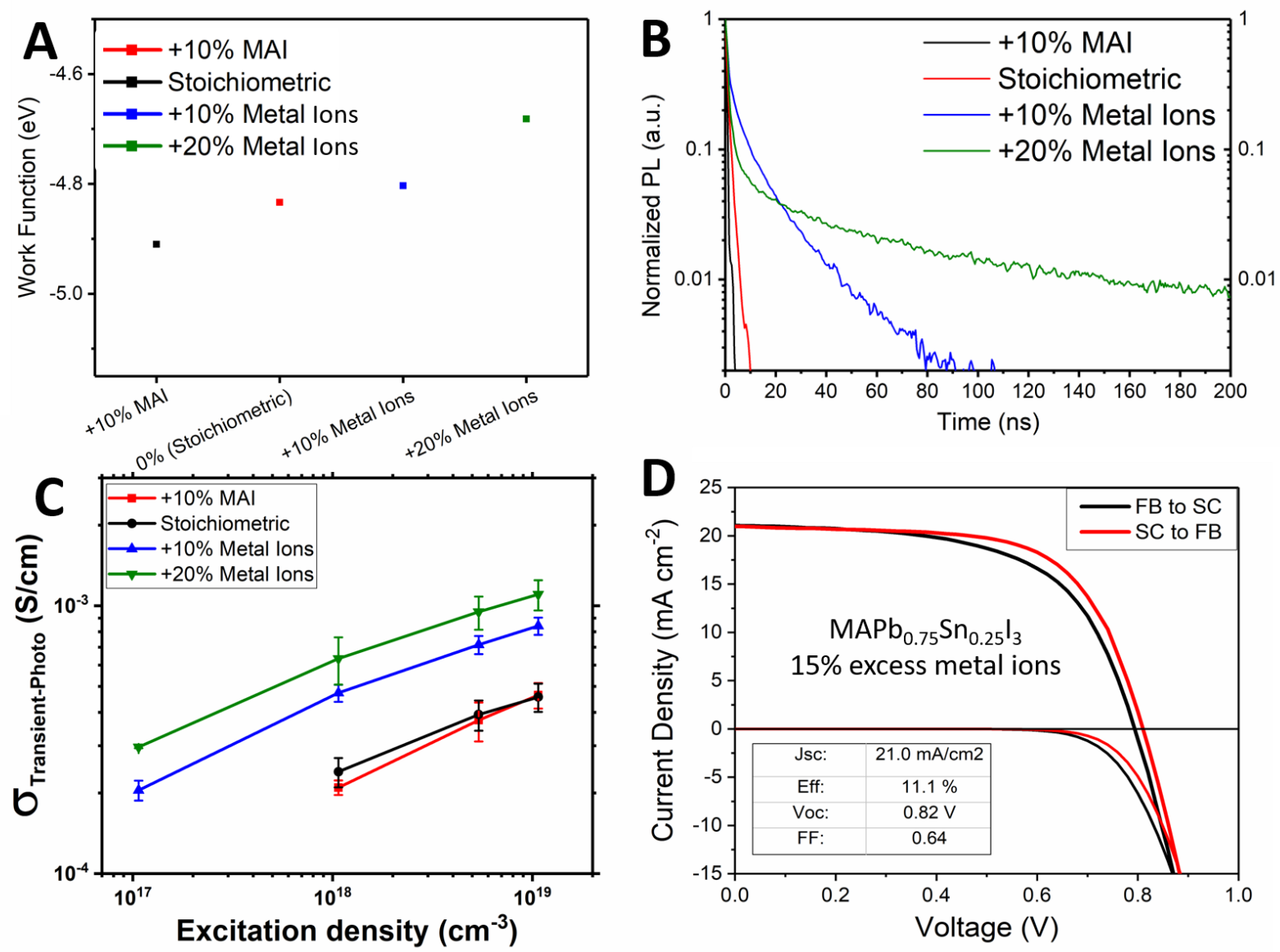

Figure 2: Impact of varying the composition of A to B-site cations for ACN processed MAPb ${ }_{0.75} S_{0.25} I_{3}$ perovskite materials.

A) Kelvin-probe measurement of varying A to B-site stoichiometry

B) Normalized time-resolved PL measurements taken at the peak emission wavelength of varying A to B-site stoichiometry

C) Peak transient photoconductivity signal as a function of $\mathrm{ns} 470 \mathrm{~nm}$ laser pulse excitation density.

D) J-V characteristics of an optimized MAPb0.75Sn0.25I3 single-junction planar heterojunction solar cell with $15 \%$

excess metal ions, measured under $100.26 \mathrm{mWcm}^{-2}$ equivalent AM1.5 irradiance, at a $0.25 \mathrm{~V} / \mathrm{s}$ scan rate. The

masked aperture area of the solar cell is $0.0919 \mathrm{~cm}^{-2}$.

Surprisingly, we found a substantial difference in optimum A-site to B-site ratio for tin-lead based perovskite materials compared to neat lead-based perovskites. In the case of $\mathrm{Sn} / \mathrm{Pb}$-based perovskite, the research community appears to have consistently observed performance gains when using an excess of tin halides, most notably in the form of tin fluoride $\left(\mathrm{SnF}_{2}\right)[45,84-87]$ or tin chloride $\left(\mathrm{SnCl}_{2}\right)$ [84]. The tin fluoride as an additive has readily been used as a reducing agent with the aim of suppressing the tin oxidation from $\mathrm{Sn}^{2+}$ to $\mathrm{Sn}^{4+}$. By suppressing oxidation, we limit $\mathrm{Sn}^{2+}$ vacancies, which causes the undesirable excessive p-type behavior found in $\mathrm{Sn}$ based perovskites. In our study here, we rely on MA to act as a reducing agent instead of $\mathrm{SnF}_{2}$,[88] since $\mathrm{SnF}_{2}$ poorly dissolves in the ACN/MA solvent system. We show in Figure $\mathrm{S} 13$ a plot of non-optimized devices with various ratios of A-site to B-site cations. We find that devices with excess MAI produced near-zero PCE and little to no short-circuit density $\left(\mathbf{J}_{\mathrm{sc}}\right)$, whereas devices with excess amounts of metals ions clearly show an increase in single junction 
device efficiency, reaching an optimum composition with $15 \%$ excess metal ions. Thus, tinbased perovskites not only require a reducing agent to suppress oxidation, but also require excess metal ions, which we assume act as "compensator" ions, to minimize the number of $\mathrm{Sn}$ vacancies. This is in agreement with the findings by Song et al., who observed that a nonstoichiometric $\mathrm{CsSnI}_{3}$ perovskite composition of 0.4:1 of $\mathrm{CsI}: \mathrm{SnI}_{2}$ was required for optimum performance when processed under a reducing hydrazine atmosphere.[89] In Figure 2A, we notice a deeper Fermi level for the $\mathrm{MAPb}_{0.75} \mathrm{Sn}_{0.25} \mathrm{I}_{3}$ perovskite with MAI rich compositions, which is consistent with a higher concentration of $\mathrm{Sn}^{2+}$ vacancies, which are expected to lead to p-doping of the perovskite. In contrast, the shallower Fermi levels, which we observed for metal ion rich perovskite films, would correspond to a more intrinsic perovskite material, indicative of fewer $\mathrm{Sn}^{2+}$ vacancies. We interpret the increase in carrier lifetimes in the perovskite absorber, which we observe in Figure $2 \mathrm{~A}$, to be consistent with and indicate a transition from a highly p-type material to a more intrinsic semiconductor.

In Figure 3, we show the structure and performance characteristics of our all-perovskite, monolithic, triple-junction solar cell, prepared via solution processing. The narrow band gap $\mathrm{MAPb}{ }_{0.75} \mathrm{Sn}_{0.25} \mathrm{I}_{3}$ perovskite solar cell, which we described in Figure 2, was processed on top of the dual-junction tandem solar cell architecture which we described in Figure1. In Figure $3 \mathrm{~A}$, we show a schematic of the $2 \mathrm{~T}$ triple-junction cell comprised of $\mathrm{FA}_{0.83} \mathrm{Cs}_{0.17} \mathrm{~Pb}\left(\mathrm{Br}_{0.7} \mathrm{I}_{0.3}\right)_{3} / \mathrm{MAPbI}_{3} / \mathrm{MAPb}_{0.75} \mathrm{Sn}_{0.25} \mathrm{I}_{3}$. In Figure 3B we show a corresponding SEM cross-section image. In Figure 3C, we show the forward and backward current-density voltage $(\mathrm{J}-\mathrm{V})$ characteristics of one of our highest-performing solar cell, measured under an equivalent irradiance of $146.86 \mathrm{~mW} \mathrm{~cm}^{-2}$. We measured a JV determined PCE of 6.7\% (6.4\% SPO, which we show in Figure S14). Our highest $V_{o c}$, which we show in Figure 3D, was measured on a separate device (shown in Figure S15) and exhibits a steady-state open-circuit voltage of $2.83 \mathrm{~V}$ after $60 \mathrm{~s}$.

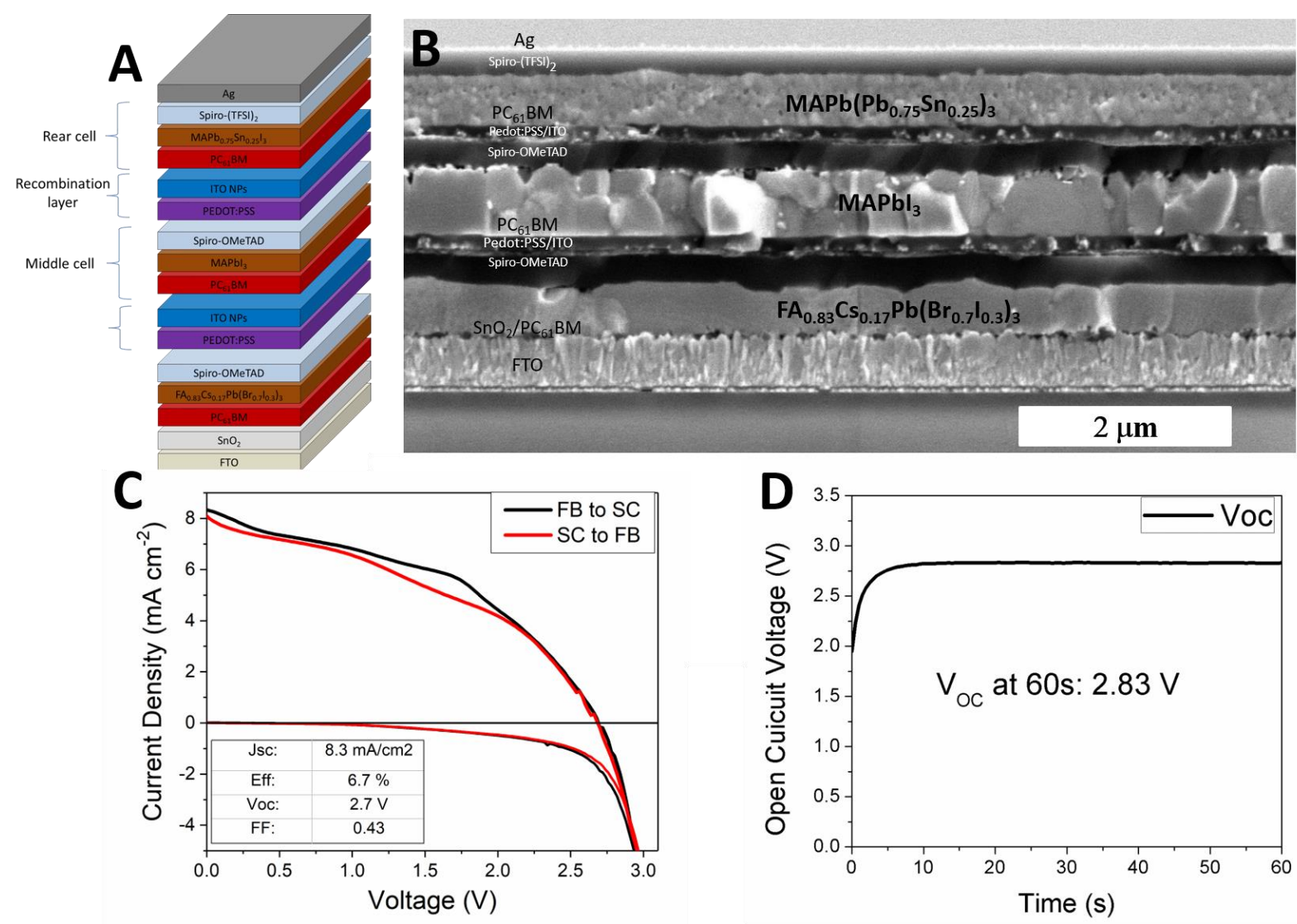

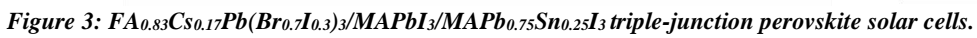

A) Schematics showing an all-solution processed triple-junction two-terminal (2T) perovskite solar cell. Incoming light will be from bellow the device.

B) SEM cross-section of the triple-junction $2 T$ all-perovskite tandem. All the layers are labeled on the image. 


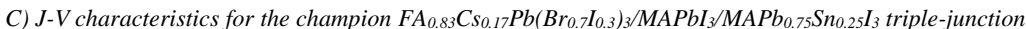
heterojunction solar cell fabricated, with an equivalent irradiance of $146.86 \mathrm{~mW} \mathrm{~cm}^{-2}$ measured at a $0.25 \mathrm{~V} / \mathrm{s}$ scan rate. The active area of the solar cell is $0.0919 \mathrm{~cm}^{-2}$.

D) Steady-state open circuit voltage $\left(V_{\text {oc }}\right)$ of triple-junction planar heterojunction perovskite solar cell measured over a 60 s time span.

We note that the performance of the triple-junction is inferior to that of the double-junction solar cell due to the lower than anticipated short-circuit current-density generated by the $\mathrm{MAPb}_{0.75} \mathrm{Sn}_{0.25} \mathrm{I}_{3}$ rear cell, and the overall low fill factor. This low photo-generated current is responsible for severely current limiting the entire multi-junction cell. In Figure S16, we show a high performing $\mathrm{FA}_{0.83} \mathrm{Cs}_{0.17} \mathrm{~Pb}_{0.5} \mathrm{Sn}_{0.5} \mathrm{I}_{3}$ perovskite in a $\mathrm{p}$-i-n architecture, processed with a DMF/DMSO solvent, filtered with a $\mathrm{FA}_{0.83} \mathrm{Cs}_{0.17} \mathrm{~Pb}\left(\mathrm{Br}_{0.7} \mathrm{I}_{0.3}\right)_{3} / \mathrm{MAPbI}_{3}$ tandem solar cell without the Ag electrode. Although we note this is not a four-terminal (4T) tandem measurement since we did not employ a semi-transparent electrode upon the top tandem stack, this measurement allows us to roughly estimate the expected efficiency gain if higher performances and lower band gaps were obtained with ACN/MA solvent system route. As we show in Figure $\mathrm{S} 16 \mathrm{c}$, a junction based on $\mathrm{FA}_{0.83} \mathrm{Cs}_{0.17} \mathrm{~Pb}_{0.5} \mathrm{Sn}_{0.5} \mathrm{I}_{3}$ with a $1.22 \mathrm{eV}$ absorption onset, $15.5 \%$ steady-state efficiency can be obtained when unfiltered, and $2.4 \%$ steady-state efficiency when filtered with the $\mathrm{FA}_{0.83} \mathrm{Cs}_{0.17} \mathrm{~Pb}\left(\mathrm{Br}_{0.7} \mathrm{I}_{0.3}\right)_{3} / \mathrm{MAPbI}_{3}$ tandem. Thus, a narrow band gap material could potentially boost the $\mathrm{FA}_{0.83} \mathrm{Cs}_{0.17} \mathrm{~Pb}\left(\mathrm{Br}_{0.7} \mathrm{I}_{0.3}\right)_{3} / \mathrm{MAPbI}_{3}$ by more than $2.4 \%$, reaching $17.5 \%$ combined PCE. We also note that this measurement includes an air gap between the tandem cell and the narrow bandgap single-junction solar cell, and an additional PEDOT:PSS layer which would otherwise not be present in the monolithic triple-junction solar cell. The EQE spectrum of the filtered cell, which we shown in Figure S16b, clearly indicates significant panchromatic loss is photocurrent density, beyond what we would expect simply from the parasitic absorbance is all the charge extraction and recombination layers, which we show in Figure S17 and S18. This loss is most likely due to the air gap, and internal reflections between the stacked (non-monolithic) sub cells.

As reported by Hörantner et al., all-perovskite triple junction solar cells employing perovskite absorbers with similar band gaps to those which we have used in the present work, should be capable of outperforming single and double-junction efficiencies. The modelling of Hörantner et al. shows that an optimized $1.22 \mathrm{eV}$ band gap material should current match the two wider band gap sub-cells of $2.04 \mathrm{eV}$ and $1.58 \mathrm{eV}$, delivering a theoretical maximum $\mathrm{J}_{\mathrm{SC}}$ of $12 \mathrm{~mA}$ $\mathrm{cm}^{-2}, \mathrm{a} \mathrm{V}_{\text {oc }}$ of $3.54 \mathrm{~V}$ and a PCE of $36.6 \%$.[64] However, this performance can only be obtained with optically transparent interlayers to reduce parasitic absorption and reflection losses. In Figure S17 and S20, we show the optical properties of each interlayer which we have used in our multi-junction stack. We note that the $\sim 60 \mathrm{~nm}$ thick $\mathrm{PC}_{61} \mathrm{BM}$ layer which we employ is responsible for the majority of the parasitic absorption and reflection losses.

To understand in more detail where our present losses are arising, and to assess the true potential of this solution processed all-perovskite multi-junction solar cell architecture, we employed a similar optical and electrical model to that used by Hörantner et al.. Using our experimental thicknesses, in combination with the extracted electrical characteristics of our best performing single junction perovskite cells of each band gap, we present in Figure 4A-B an estimation of the performance of our tandem stack, and the corresponding modeled external quantum efficiency spectrum. We estimate that our tandem solar cell (sub cells with $1.94 \mathrm{eV}$ and $1.57 \mathrm{eV}$ bandgaps) can be increased to nearly $19 \%$ by combining the electrical characteristics of our current measured champion $\mathrm{FA}_{0.83} \mathrm{Cs}_{0.17} \mathrm{~Pb}\left(\mathrm{Br}_{0.7} \mathrm{I}_{0.3}\right)_{3}$ with our best-inclass $\mathrm{ACN} / \mathrm{MA} \mathrm{MAPbI}{ }_{3}$ device. We then proceed to model a stack with identical absorber and interlayer materials (shown in Figure 4C-D), but with a state of the art $\mathrm{MAPbI}_{3}$, processed via a DMF/DMSO route, an optimized perovskite thicknesses, interlayers with thickness' down to $50 \mathrm{~nm}$, and $\mathrm{agF}_{2}$ anti-reflective coating. These improvements allow the tandem cell to reach a $21.8 \%$ PCE. In this figure, we also modeled an optimized stack with an enhanced front cell with improved electrical characteristics, assuming an electroluminescence efficiency $\left(E Q E_{E L}\right)$ of $1 \%$, a series resistance $\left(R_{S}\right)$ of $4 \cdot 10^{-2} \Omega \mathrm{cm}^{2}$ and a shunt resistance $\left(R_{S H}\right)$ of $10 \mathrm{M} \Omega \mathrm{cm}^{2}$ for the $\mathrm{FA}_{0.83} \mathrm{Cs}_{0.17} \mathrm{~Pb}\left(\mathrm{Br}_{0.7} \mathrm{I}_{0.3}\right)_{3},[90]$ which increased the front cell PCE to $16.8 \%$, and the attainable tandem cell PCE to $26.8 \%$. Figures $4 \mathrm{E}-\mathrm{F}$ reveal the performance of our triple junction architecture, assuming perovskite thicknesses optimized for current-matching with maximum thickness limited to $1382 \mathrm{~nm}$, state-of-art $\mathrm{MAPb}_{3}$ and $\mathrm{FA}_{0.6} \mathrm{MA}_{0.4} \mathrm{~Pb}_{0.4} \mathrm{Sn}_{0.6} \mathrm{I}_{3}$ perovskite sub-cells, and an anti-reflective coating is added on top. We can see that a $26.7 \%$ PCE can be achieved by using optimized thickness, and over 30\% PCE triple junction efficiency is within reach by using the enhanced front cell. We detail the specific layer thicknesses for each simulation, along with further details in the supplementary information. 

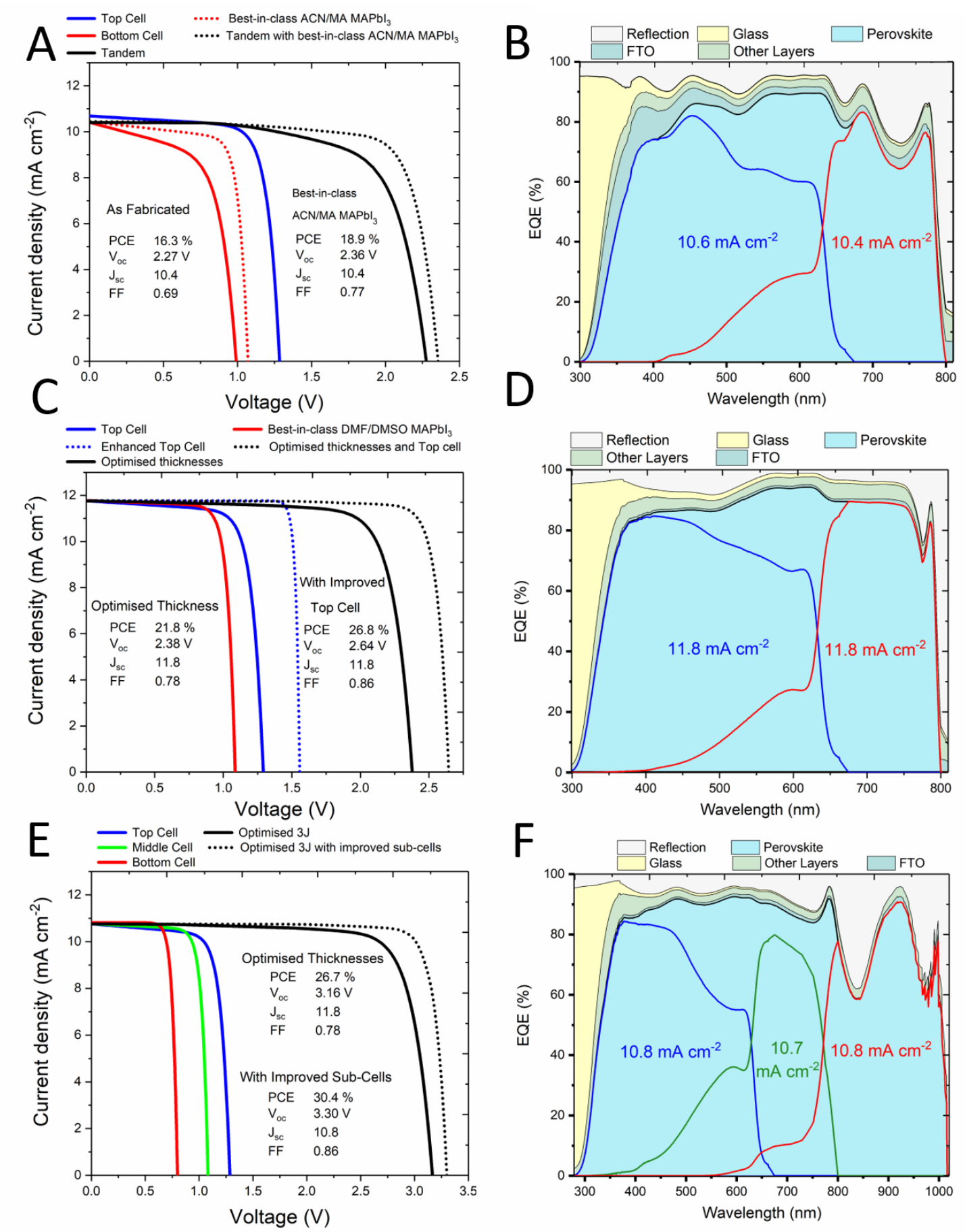

Figure 4: Optical and electrical modelling of multi-junction perovskite solar cells.

A) Calculated J-V characteristics and

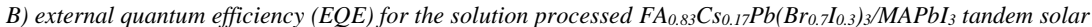
cell, with current single junction experimental data and with best-in-class ACN/MA MAPbI single junction cell. C) Calculated J-V characteristics and

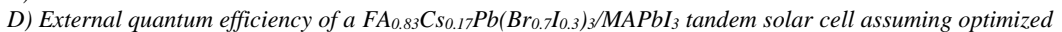
layers thicknesses, $50 \mathrm{~nm}$ interlayers, $\mathrm{Mg} \mathrm{F}_{2}$ anti-reflection coating, and an enhanced TC performance.

E) $J$-V characteristics and

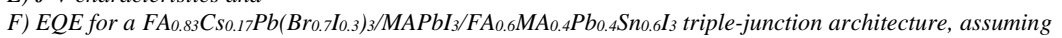
optimized layers thicknesses, $50 \mathrm{~nm}$ interlayers, $\mathrm{MgF}_{2}$ anti-reflection coating, and an enhanced TC performance. 
To date, all-perovskite monolithic multi-junction solar cells have yet to surpass the efficiency of their state-of-the-art single-junction counterparts. The perovskite-on-silicon tandem cell is the only example yet realized which delivers greater efficiency than the world record for each sub-cell.[91] The perovskite junctions require significant improvements in light management to reduce reflection and parasitic absorption losses. The most significant fundamental loss is the inability to generate a comparatively high $\mathrm{V}_{\mathrm{oc}}$ from the wide band gap cells. Furthermore, layer deposition uniformity has to be improved, in order to realize charge extraction and recombination layers with thicknesses in the $50 \mathrm{~nm}$ range. However, with concerted effort, we expect these losses to be mitigated, and hence enable fully-solution processed multi-junction cells to ultimately surpass state-of-the-art single-junction cell efficiencies.

\section{SUPPLEMENTAL INFORMATION}

Supplemental Information includes experimental procedures, 19 figures, 3 tables and 1 video. The Supplementary Video is a comparison between DMF/DMSO and ACN/MA solvent systems for tandem applications.

\section{AUTHOR CONTRIBUTIONS}

D.P.M and H.J.S. conceived the experiments. S.M conducted the optical and electrical modelling of multi-junction perovskite. D.P.M., S.M, N.K.N., M.T.K., J.L., J.H.W., J.M.B., conducted the experiments. D.P.M wrote the original draft of the manuscript. H.J.S. supervised the project. L.M.H. and M.B.J. provided advice and expertise. All authors contributed to the final version of the manuscript.

\section{ACKNOWLEDGMENTS}

This project was funded in part by EPSRC UK and the U.S. Office of Naval Research (ONR). The authors would like to acknowledge Dr. Severin N. Habisreutinger from the National Renewable Energy Laboratory for his valuable and enticing discussions on recombination layers comprised of carbon nanotubes.

\section{DECLARATION OF INTERESTS}

HJS is a co-founder, Chief Scientific Officer and a Director of Oxford PV Ltd. Oxford University have filed a patent related to the subject matter of this manuscript.

\section{REFERENCES AND NOTES}

[1] Sadhanala A, Deschler F, Thomas TH, Dutton SE, Goedel KC, Hanusch FC, et al. Preparation of Single-Phase Films of CH3NH3Pb(I1-xBrx)3 with Sharp Optical Band Edges. J Phys Chem Lett 2014;5:2501-5. doi:10.1021/jz501332v.

[2] Dou L, Yang Y (Micheal), You J, Hong Z, Chang W-H, Li G, et al. Solution-processed hybrid perovskite photodetectors with high detectivity. Nat Commun 2014;5:5404. doi:10.1038/ncomms6404.

[3] Fang Y, Dong Q, Shao Y, Yuan Y, Huang J. Highly narrowband perovskite single-crystal photodetectors enabled by surface-charge recombination. Nat Photonics 2015;9:679-86. doi:10.1038/nphoton.2015.156.

[4] Jia Y, Kerner RA, Grede AJ, Rand BP, Giebink NC. Continuous-wave lasing in an organic-inorganic lead halide perovskite semiconductor. Nat Photonics 2017;11:784-8. doi:10.1038/s41566-017-0047-6.

[5] Zhu H, Fu Y, Meng F, Wu X, Gong Z, Ding Q, et al. Lead halide perovskite nanowire lasers with low lasing thresholds and high quality factors. Nat Mater 2015;14:636-42. doi:10.1038/nmat4271.

[6] Kojima A, Teshima K, Shirai Y, Miyasaka T. Organometal Halide Perovskites as Visible-Light Sensitizers for Photovoltaic Cells. J Am Chem Soc 2009;131:6050-1. doi:10.1021/ja809598r.

[7] Lee MM, Teuscher J, Miyasaka T, Murakami TN, Snaith HJ. Efficient Hybrid Solar Cells Based on Meso-Superstructured Organometal Halide Perovskites. Science 2012;338:643-7. doi:10.1126/science.1228604.

[8] Liu M, Johnston MB, Snaith HJ. Efficient planar heterojunction perovskite solar cells by vapour deposition. Nature 2013;501:395-8. doi:10.1038/nature12509.

[9] Burschka J, Pellet N, Moon S-J, Humphry-Baker R, Gao P, Nazeeruddin MK, et al. Sequential deposition as a route to high-performance perovskite-sensitized solar cells. Nature 2013;499:316-9. doi:10.1038/nature12340.

[10] Malinkiewicz O, Yella A, Lee YH, Espallargas GM, Graetzel M, Nazeeruddin MK, et al. Perovskite solar cells employing organic charge-transport layers. Nat Photonics 2013;8:128-32. doi:10.1038/nphoton.2013.341.

[11] Stranks SD, Eperon GE, Grancini G, Menelaou C, Alcocer MJP, Leijtens T, et al. 
Electron-hole diffusion lengths exceeding 1 micrometer in an organometal trihalide perovskite absorber. Science 2013;342:341-4. doi:10.1126/science.1243982.

[12] Kim H-S, Lee C-R, Im J-H, Lee K-B, Moehl T, Marchioro A, et al. Lead Iodide Perovskite Sensitized All-Solid-State Submicron Thin Film Mesoscopic Solar Cell with Efficiency Exceeding 9\%. Sci Rep 2012;2:591. doi:10.1038/srep00591.

[13] Im J-H, Lee C-R, Lee J-W, Park S-W, Park N-G. 6.5\% Efficient Perovskite QuantumDot-Sensitized Solar Cell. Nanoscale 2011;3:4088-93. doi:10.1039/c1nr10867k.

[14] Eperon GE, Stranks SD, Menelaou C, Johnston MB, Herz LM, Snaith HJ. Formamidinium lead trihalide: a broadly tunable perovskite for efficient planar heterojunction solar cells. Energy Environ Sci 2014;7:982-8. doi:10.1039/c3ee43822h.

[15] Noh JH, Im SH, Heo JH, Mandal TN, Seok S Il. Chemical management for colorful, efficient, and stable inorganic-organic hybrid nanostructured solar cells. Nano Lett 2013;13:1764-9. doi:10.1021/nl400349b.

[16] Shockley W, Queisser HJ. Detailed Balance Limit of Efficiency of $p$ - $n$ Junction Solar Cells. J Appl Phys 1961;32:510-9. doi:10.1063/1.1736034.

[17] Tiedje T, Yablonovitch E, Cody GD, Brooks BG. Limiting efficiency of silicon solar cells. IEEE Trans Electron Devices 1984;31:711-6. doi:10.1109/T-ED.1984.21594.

[18] Hirst LC, Ekins-Daukes NJ. Fundamental losses in solar cells. Prog Photovoltaics Res Appl 2011;19:286-93. doi:10.1002/pip.1024.

[19] Araújo GL, Martí A. Absolute limiting efficiencies for photovoltaic energy conversion. Sol Energy Mater Sol Cells 1994;33:213-40. doi:10.1016/0927-0248(94)90209-7.

[20] McMeekin DP, Sadoughi G, Rehman W, Eperon GE, Saliba M, Horantner MT, et al. A mixed-cation lead mixed-halide perovskite absorber for tandem solar cells. Science 2016;351:151-5. doi:10.1126/science.aad5845.

[21] Beal RE, Slotcavage DJ, Leijtens T, Bowring AR, Belisle RA, Nguyen WH, et al. Cesium Lead Halide Perovskites with Improved Stability for Tandem Solar Cells. J Phys Chem Lett 2016;7:746-51. doi:10.1021/acs.jpclett.6b00002.

[22] Li Z, Yang M, Park J-S, Wei S-H, Berry JJ, Zhu K. Stabilizing Perovskite Structures by Tuning Tolerance Factor: Formation of Formamidinium and Cesium Lead Iodide SolidState Alloys. Chem Mater 2016;28:284-92. doi:10.1021/acs.chemmater.5b04107.

[23] Sutton RJ, Eperon GE, Miranda L, Parrott ES, Kamino BA, Patel JB, et al. BandgapTunable Cesium Lead Halide Perovskites with High Thermal Stability for Efficient Solar Cells. Adv Energy Mater 2016;6:n/a-n/a. doi:10.1002/aenm.201502458.

[24] Rajagopal A, Yang Z, Jo SB, Braly IL, Liang P-W, Hillhouse HW, et al. Highly Efficient Perovskite-Perovskite Tandem Solar Cells Reaching $80 \%$ of the Theoretical Limit in Photovoltage. Adv Mater 2017;29:1702140. doi:10.1002/adma.201702140.

[25] Chen S, Hou Y, Chen H, Tang X, Langner S, Li N, et al. Exploring the Stability of Novel Wide Bandgap Perovskites by a Robot Based High Throughput Approach. Adv Energy Mater 2017:1701543. doi:10.1002/aenm.201701543.

[26] Saliba M, Matsui T, Seo J-Y, Domanski K, Correa-Baena J-P, Mohammad K. N, et al. Cesium-containing Triple Cation Perovskite Solar Cells: Improved Stability, Reproducibility and High Efficiency. Energy Environ Sci 2016. doi:10.1039/C5EE03874J.

[27] Wang Z, Lin Q, Chmiel FP, Sakai N, Herz LM, Snaith HJ. Efficient and ambient-airstable solar cells with 2D-3D hetero-structured butylammonium-caesium-formamidinium lead halide perovskites. Nat Energy 2017;2:17135. doi:10.1038/nenergy.2017.135.

[28] Lee J-W, Kim D-H, Kim H-S, Seo S-W, Cho SM, Park N-G. Formamidinium and Cesium Hybridization for Photo- and Moisture-Stable Perovskite Solar Cell. Adv Energy Mater 2015;5:1501310. doi:10.1002/aenm.201501310.

[29] Yi C, Luo J, Meloni S, Boziki A, Ashari-Astani N, Grätzel C, et al. Entropic Stabilization of Mixed A-Cation $\mathrm{ABX}_{3}$ Metal Halide Perovskites for High Performance Perovskite Solar Cells. Energy Environ Sci 2015;9:656-62. doi:10.1039/C5EE03255E.

[30] Kulbak M, Gupta S, Kedem N, Levine I, Bendikov T, Hodes G, et al. Cesium Enhances Long-Term Stability of Lead Bromide Perovskite-Based Solar Cells. J Phys Chem Lett 2016;7:167-72. doi:10.1021/acs.jpclett.5b02597.

[31] Stoumpos CC, Malliakas CD, Kanatzidis MG. Semiconducting tin and lead iodide perovskites with organic cations: phase transitions, high mobilities, and near-infrared photoluminescent properties. Inorg Chem 2013;52:9019-38. doi:10.1021/ic401215x.

[32] Noel NK, Stranks SD, Abate A, Wehrenfennig C, Guarnera S, Haghighirad A-A, et al. Lead-free organic-inorganic tin halide perovskites for photovoltaic applications. Energy Environ Sci 2014:7:3061-8. doi:10.1039/C4EE01076K.

[33] Hao F, Stoumpos CC, Chang RPH, Kanatzidis MG. Anomalous Band Gap Behavior in Mixed $\mathrm{Sn}$ and $\mathrm{Pb}$ Perovskites Enables Broadening of Absorption Spectrum in Solar Cells. J Am Chem Soc 2014;136:8094-9. doi:10.1021/ja5033259.

[34] Yang Z, Rajagopal A, Chueh C-C, Jo SB, Liu B, Zhao T, et al. Stable Low-Bandgap PbSn Binary Perovskites for Tandem Solar Cells. Adv Mater 2016;28:8990-7. doi:10.1002/adma.201602696.

[35] Rajagopal A, Liang P-W, Chueh C-C, Yang Z, Jen AK-Y. Defect Passivation via a Graded Fullerene Heterojunction in Low-Bandgap $\mathrm{Pb}-\mathrm{Sn}$ Binary Perovskite 
Photovoltaics. ACS Energy Lett 2017;2:2531-9. doi:10.1021/acsenergylett.7b00847.

[36] Li L, Zhang F, Hao Y, Sun Q, Li Z, Wang H, et al. High efficiency planar Sn-Pb binary perovskite solar cells: controlled growth of large grains via a one-step solution fabrication process. J Mater Chem C 2017;5:2360-7. doi:10.1039/C6TC05325D.

[37] Lee S, Kang D-W. Highly Efficient and Stable Sn-Rich Perovskite Solar Cells by Introducing Bromine. ACS Appl Mater Interfaces 2017;9:22432-9. doi:10.1021/acsami.7b04011.

[38] Liao W, Zhao D, Yu Y, Shrestha N, Ghimire K, Grice CR, et al. Fabrication of Efficient Low-Bandgap Perovskite Solar Cells by Combining Formamidinium Tin Iodide with Methylammonium Lead Iodide. J Am Chem Soc 2016;138:12360-3. doi:10.1021/jacs.6b08337.

[39] Eperon GE, Leijtens T, Bush KA, Prasanna R, Green T, Wang JT-W, et al. Perovskiteperovskite tandem photovoltaics with optimized band gaps. Science 2016;354:861-5. doi:10.1126/science.aaf9717.

[40] NREL. NREL Efficiency chart 2018. https://www.nrel.gov/pv/assets/images/efficiencychart-20180716.jpg (accessed November 23, 2018).

[41] Kagan CR, Mitzi DB, Dimitrakopoulos CD. Organic-Inorganic Hybrid Materials as Semiconducting Channels in Thin-Film Field-Effect Transistors. Science 1999;286:9457. doi:10.1126/science.286.5441.

[42] Bailie CD, Christoforo MG, Mailoa JP, Bowring AR, Unger EL, Nguyen WH, et al. Semi-transparent perovskite solar cells for tandems with silicon and CIGS. Energy Environ Sci 2015;8:956-63. doi:10.1039/C4EE03322A.

[43] Werner J, Barraud L, Walter A, Bräuninger M, Sahli F, Sacchetto D, et al. Efficient Near-Infrared-Transparent Perovskite Solar Cells Enabling Direct Comparison of 4Terminal and Monolithic Perovskite/Silicon Tandem Cells. ACS Energy Lett 2016;1:474-80. doi:10.1021/acsenergylett.6b00254.

[44] Pisoni S, Fu F, Feurer T, Makha M, Bissig B, Nishiwaki S, et al. Flexible NIRtransparent perovskite solar cells for all-thin-film tandem photovoltaic devices. J Mater Chem A 2017;5:13639-47. doi:10.1039/C7TA04225F.

[45] Zhao D, Yu Y, Wang C, Liao W, Shrestha N, Grice CR, et al. Low-bandgap mixed tinlead iodide perovskite absorbers with long carrier lifetimes for all-perovskite tandem solar cells. Nat Energy 2017;2:17018. doi:10.1038/nenergy.2017.18

[46] Duong T, Wu Y, Shen H, Peng J, Fu X, Jacobs D, et al. Rubidium Multication Perovskite with Optimized Bandgap for Perovskite-Silicon Tandem with over 26\% Efficiency. Adv Energy Mater 2017;7:1700228. doi:10.1002/aenm.201700228.

[47] Shen H, Duong T, Peng J, Jacobs D, Wu N, Gong J, et al. Mechanically-stacked perovskite/CIGS tandem solar cells with efficiency of $23.9 \%$ and reduced oxygen sensitivity. Energy Environ Sci 2018;11:394-406. doi:10.1039/C7EE02627G.

[48] Todorov T, Gershon T, Gunawan O, Sturdevant C, Guha S. Perovskite-kesterite monolithic tandem solar cells with high open-circuit voltage. Appl Phys Lett 2014:105:173902. doi:10.1063/1.4899275.

[49] Werner J, Weng C-H, Walter A, Fesquet L, Seif JP, De Wolf S, et al. Efficient Monolithic Perovskite/Silicon Tandem Solar Cell with Cell Area \&gt; $1 \mathrm{~cm}^{2}$. J Phys Chem Lett 2016;7:161-6. doi:10.1021/acs.jpclett.5b02686.

[50] Forgács D, Gil-Escrig L, Pérez-Del-Rey D, Momblona C, Werner J, Niesen B, et al Efficient Monolithic Perovskite/Perovskite Tandem Solar Cells. Adv Energy Mater 2017;7:1602121. doi:10.1002/aenm.201602121.

[51] Sahli F, Werner J, Kamino BA, Bräuninger M, Monnard R, Paviet-Salomon B, et al. Fully textured monolithic perovskite/silicon tandem solar cells with $25.2 \%$ power conversion efficiency. Nat Mater 2018:1. doi:10.1038/s41563-018-0115-4.

[52] Han Q, Hsieh Y-T, Meng L, Wu J-L, Sun P, Yao E-P, et al. High-performance perovskite/Cu(In, Ga)Se2 monolithic tandem solar cells. Science 2018;361:904-8. doi:10.1126/science.aat5055.

[53] Zhao D, Chen C, Wang C, Junda MM, Song Z, Grice CR, et al. Efficient two-terminal all-perovskite tandem solar cells enabled by high-quality low-bandgap absorber layers. Nat Energy 2018:1. doi:10.1038/s41560-018-0278-x.

[54] Bush KA, Palmstrom AF, Yu ZJ, Boccard M, Cheacharoen R, Mailoa JP, et al. 23.6\%efficient monolithic perovskite/silicon tandem solar cells with improved stability. Nat Energy 2017;2:17009. doi:10.1038/nenergy.2017.9.

[55] Albrecht S, Saliba M, Correa Baena JP, Lang F, Kegelmann L, Mews M, et al. Monolithic perovskite/silicon-heterojunction tandem solar cells processed at low temperature. Energy Environ Sci 2016;9:81-8. doi:10.1039/C5EE02965A.

[56] Sheng R, Hoerantner MT, Wang Z, Jiang Y, Zhang W, Agosti A, et al. Monolithic Wide Band Gap Perovskite/ Perovskite Tandem Solar Cells with Organic Recombination Layers. J Phys Chem C 2017:acs.jpcc.7b05517. doi:10.1021/acs.jpcc.7b05517.

[57] Zhao D, Wang C, Song Z, Yu Y, Chen C, Zhao X, et al. Four-Terminal All-Perovskite Tandem Solar Cells Achieving Power Conversion Efficiencies Exceeding 23\%. ACS Energy Lett 2018:305-6. doi:10.1021/acsenergylett.7b01287.

[58] Ávila J, Momblona C, Boix P, Sessolo M, Anaya M, Lozano G, et al. High voltage 
vacuum-deposited $\mathrm{CH}_{3} \mathrm{NH}_{3} \mathrm{PbI}_{3}-\mathrm{CH}_{3} \mathrm{NH}_{3} \mathrm{PbI}_{3}$ tandem solar cells. Energy Environ Sci 2018;11:3292-7. doi:10.1039/C8EE01936C.

[59] Werner J, Sahli F, Fu F, Diaz Leon JJ, Walter A, Kamino BA, et al.

Perovskite/Perovskite/Silicon Monolithic Triple-Junction Solar Cells with a Fully Textured Design. ACS Energy Lett 2018;3:2052-8. doi:10.1021/acsenergylett.8b01165.

[60] Jiang F, Liu T, Luo B, Tong J, Qin F, Xiong S, et al. A two-terminal perovskite/perovskite tandem solar cell. J Mater Chem A 2016;4:1208-13. doi:10.1039/C5TA08744A.

[61] Wu Y, Yan D, Peng J, Duong T, Wan Y, Phang SP, et al. Monolithic perovskite/siliconhomojunction tandem solar cell with over $22 \%$ efficiency. Energy Environ Sci 2017;10:2472-9. doi:10.1039/C7EE02288C.

[62] Ellmer K. Past achievements and future challenges in the development of optically transparent electrodes. Nat Photonics 2012;6:809-17. doi:10.1038/nphoton.2012.282.

[63] Zhao D, Yu Y, Wang C, Liao W, Shrestha N, Grice CR, et al. Low-bandgap mixed tinlead iodide perovskite absorbers with long carrier lifetimes for all-perovskite tandem solar cells. Nat Energy 2017;2:17018. doi:10.1038/nenergy.2017.18

[64] Hörantner MT, Leijtens T, Ziffer ME, Eperon GE, Christoforo MG, McGehee MD, et al. The Potential of Multijunction Perovskite Solar Cells. ACS Energy Lett 2017;2:2506-13. doi:10.1021/acsenergylett.7b00647.

[65] Noel NK, Habisreutinger SN, Wenger B, Klug MT, Hörantner MT, Johnston MB, et al. A low viscosity, low boiling point, clean solvent system for the rapid crystallisation of highly specular perovskite films. Energy Environ Sci 2017;10:145-52. doi:10.1039/C6EE02373H.

[66] Tang Z, Bessho T, Awai F, Kinoshita T, Maitani MM, Jono R, et al. Hysteresis-free perovskite solar cells made of potassium-doped organometal halide perovskite. Sci Rep 2017;7:12183. doi:10.1038/s41598-017-12436-x.

[67] Nam JK, Chai SU, Cha W, Choi YJ, Kim W, Jung MS, et al. Potassium Incorporation for Enhanced Performance and Stability of Fully Inorganic Cesium Lead Halide Perovskite Solar Cells. Nano Lett 2017;17:2028-33. doi:10.1021/acs.nanolett.7b00050.

[68] Muzammal uz Zaman M, Imran M, Saleem A, Kamboh AH, Arshad M, Khan NA, et al. Potassium doped methylammonium lead iodide (MAPbI3) thin films as a potential absorber for perovskite solar cells; structural, morphological, electronic and optoelectric properties. Phys B Condens Matter 2017;522:57-65. doi:10.1016/J.PHYSB.2017.07.067.

[69] Bu T, Liu X, Zhou Y, Yi J, Huang X, Luo L, et al. A novel quadruple-cation absorber for universal hysteresis elimination for high efficiency and stable perovskite solar cells. Energy Environ Sci 2017;10:2509-15. doi:10.1039/C7EE02634J.

[70] Abdi-Jalebi M, Andaji-Garmaroudi Z, Cacovich S, Stavrakas C, Philippe B, Richter JM, et al. Maximizing and stabilizing luminescence from halide perovskites with potassium passivation. Nature 2018;555:497-501. doi:10.1038/nature25989.

[71] McMeekin DP, Wang Z, Rehman W, Pulvirenti F, Patel JB, Noel NK, et al. Crystallization Kinetics and Morphology Control of Formamidinium-Cesium MixedCation Lead Mixed-Halide Perovskite via Tunability of the Colloidal Precursor Solution. Adv Mater 2017:1607039. doi:10.1002/adma.201607039.

[72] Rehman W, Milot RL, Eperon GE, Wehrenfennig C, Boland JL, Snaith HJ, et al. ChargeCarrier Dynamics and Mobilities in Formamidinium Lead Mixed-Halide Perovskites. Adv Mater 2015:n/a-n/a. doi:10.1002/adma.201502969.

[73] Abdi-Jalebi M, Andaji-Garmaroudi Z, Cacovich S, Stavrakas C, Philippe B, Richter JM, et al. Maximising and Stabilising Luminescence in Metal Halide Perovskite Device Structures n.d.

[74] Snaith HJ, Abate A, Ball JM, Eperon GE, Leijtens T, Noel NK, et al. Anomalous Hysteresis in Perovskite Solar Cells. J Phys Chem Lett 2014;5:1511-5. doi:10.1021/jz500113x.

[75] McMeekin DP, Sadoughi G, Rehman W, Eperon GE, Saliba M, Hörantner MT, et al. A mixed-cation lead mixed-halide perovskite absorber for tandem solar cells. Science 2016;351:151-5. doi:10.1126/science.aad5845.

[76] Roldán-Carmona C, Gratia P, Zimmermann I, Grancini G, Gao P, Graetzel M, et al. High efficiency methylammonium lead triiodide perovskite solar cells: the relevance of nonstoichiometric precursors. Energy Environ Sci 2015;8:3550-6. doi:10.1039/C5EE02555A.

[77] Yang M, Li Z, Reese MO, Reid OG, Kim DH, Siol S, et al. Perovskite ink with wide processing window for scalable high-efficiency solar cells. Nat Energy 2017;2:17038 doi:10.1038/nenergy.2017.38.

[78] Bi D, Tress W, Dar MI, Gao P, Luo J, Renevier C, et al. Efficient luminescent solar cells based on tailored mixed-cation perovskites. Sci Adv 2016;2:e1501170-e1501170. doi:10.1126/sciadv.1501170.

[79] Chen Q, Zhou H, Song T-B, Luo S, Hong Z, Duan H-S, et al. Controllable Self-Induced Passivation of Hybrid Lead Iodide Perovskites toward High Performance Solar Cells. Nano Lett 2014;14:4158-63. doi:10.1021/n1501838y.

[80] Jacobsson TJ, Correa-Baena J-P, Halvani Anaraki E, Philippe B, Stranks SD, Bouduban 
MEF, et al. Unreacted $\mathrm{PbI}_{2}$ as a Double-Edged Sword for Enhancing the Performance of Perovskite Solar Cells. J Am Chem Soc 2016;138:10331-43. doi:10.1021/jacs.6b06320.

[81] Liu J, Pathak SK, Sakai N, Sheng R, Bai S, Wang Z, et al. Identification and Mitigation of a Critical Interfacial Instability in Perovskite Solar Cells Employing Copper Thiocyanate Hole-Transporter. Adv Mater Interfaces 2016;3:1600571. doi:10.1002/admi.201600571.

[82] Eperon GE, Hörantner MT, Snaith HJ. Metal halide perovskite tandem and multiplejunction photovoltaics. Nat Rev Chem 2017;1:0095. doi:10.1038/s41570-017-0095.

[83] Leijtens T, Lim J, Teuscher J, Park T, Snaith HJ. Charge Density Dependent Mobility of Organic Hole-Transporters and Mesoporous $\mathrm{TiO}_{2}$ Determined by Transient Mobility Spectroscopy: Implications to Dye-Sensitized and Organic Solar Cells. Adv Mater 2013;25:3227-33. doi:10.1002/adma.201300947.

[84] Marshall KP, Walker M, Walton RI, Hatton RA. Enhanced stability and efficiency in hole-transport-layer-free CsSnI3 perovskite photovoltaics. Nat Energy 2016;1:16178. doi:10.1038/nenergy.2016.178.

[85] Lee SJ, Shin SS, Kim YC, Kim D, Ahn TK, Noh JH, et al. Fabrication of Efficient Formamidinium Tin Iodide Perovskite Solar Cells through $\mathrm{SnF}_{2}-$ Pyrazine Complex. J Am Chem Soc 2016;138:3974-7. doi:10.1021/jacs.6b00142.

[86] Kumar MH, Dharani S, Leong WL, Boix PP, Prabhakar RR, Baikie T, et al. Lead-Free Halide Perovskite Solar Cells with High Photocurrents Realized Through Vacancy Modulation. Adv Mater 2014;26:7122-7. doi:10.1002/adma.201401991.

[87] Kontos AG, Kaltzoglou A, Siranidi E, Palles D, Angeli GK, Arfanis MK, et al. Structural Stability, Vibrational Properties, and Photoluminescence in $\mathrm{CsSnI}_{3}$ Perovskite upon the Addition of $\mathrm{SnF}_{2}$. Inorg Chem 2017;56:84-91. doi:10.1021/acs.inorgchem.6b02318.

[88] and JDSN, Blanchard* GJ. Formation of Gold Nanoparticles Using Amine Reducing Agents 2006. doi:10.1021/LA060045Z.

[89] Song T-B, Yokoyama T, Aramaki S, Kanatzidis MG. Performance Enhancement of Lead-Free Tin-Based Perovskite Solar Cells with Reducing Atmosphere-Assisted Dispersible Additive. ACS Energy Lett 2017;2:897-903. doi:10.1021/acsenergylett.7b00171.

[90] Hörantner MT, Snaith HJ. Predicting and optimising the energy yield of perovskite-onsilicon tandem solar cells under real world conditions. Energy Environ Sci 2017;10:1983-93. doi:10.1039/C7EE01232B.

[91] Oxford PV. Oxford PV sets world record for perovskite solar cell |Oxford PV 2018:1. https://www.oxfordpv.com/news/oxford-pv-sets-world-record-perovskite-solar-cell. 